\title{
Марценюк В.B. \\ Сорбция никеля из водных растворов полимерными электретами на основе реактопластов
}

ФГБОУ ВО «Санкт-Петербургский государственный университет промышленных технологий и дизайна» doi: 10.18411/trnio-01-2022-66

(Россия, Санкт-Петербург)

\section{Аннотация}

Проведена оценка возможности применения полимерных электретов на основе реактопластов в качестве сорбентов. Методом спектрофотометрического титрования определена концентрация катионов никеля до и после сорбции. Показано, что оптимальная продолжительность сорбции катионов никеля составляет от 5 до 15 минут. В течение данной продолжительности удаётся снизить концентрацию катионов никеля в растворе более чем на 40 \%. Для повышения сорбционных свойств предложены приёмы интенсификации процесса.

Ключевые слова: термореактивные смолы, электреты, полимерный электрет, практическое применение, сорбция, спектрофотометрическое титрование, катионы никеля.

\section{Abstract}

The possibility of using polymer electrets based on thermoset resins as sorbents has been demonstrated. Nickel cations were determined by spectrophotometry titration before and after sorption one. It is shown that the optimal duration of the sorption for nickel cations is from 5 to 15 minutes. During this duration, it is possible to reduce the concentration of nickel cations in the solution by more than $40 \%$. To increase the sorption properties, methods of intensifying the process are proposed.

Keywords: thermosetting resins, electrets, polymer electret, practical application, sorption, spectrophotometric titration, nickel cations.

Ранее в ряде работ [1-4] продемонстрирована технология полимерных электретов на основе реактопластов и их практическое применение. Отличие данной технологии от существующих приёмов принудительной поляризации (инжекция заряда), применяемых для термопластичных полимеров, заключается в поляризации олигомерного связующего в процессе отверждения и превращения в сетчатый полимер. Такой подход позволяет удешевить технологию, а также получить более стабильные во времени полимерные электреты, так как центры поляризации закреплены в сшитой структуре термопласта.

Для модификации полимерных электретов на основе реактопластов с целью увеличения их электретных свойств (повышение ёмкости и поверхностной плотности электрического заряда) применяют различные методы. Например, для ускорения процесса отверждения олигомерной композиции и увеличения разности скоростей отверждения между сторонами образца, что является движущей силой процесса отвердительной поляризации, применяют воздействие ультрафиолетового излучения [5]. Также для полимерных электретов на основе реактопластов применим стандартный для всех электретов метод физической модификации внешним постоянным электрическим полем [6]. В процессе обработки неотвержденных смесей олигомерной смолы с отвердителем в постоянном электрическом поле происходит процесс ориентации диполей между сторонами электрета. Это приводит, в зависимости от полярности внешнего постоянного электрического поля, к образованию гомо- и гетерозарядов.

Одним из практических применений полимерных электретов является использование их в качестве электретной мембраны в конденсаторных микрофонах. Такие электретные мембраны имеют меньший на один-два порядка величины модуль упругости, чем традиционные металлические мембраны. Благодаря этому собственные частоты электретной мембраны значительно меньше собственных частот металлической, следовательно, через электретную мембрану не записываются высокочастотные металлические обертоны. Другой 
областью применения полимерных электретов может быть сорбция металлов для очистки сточных вод производств. Поэтому целью данной работы стало изучение применения новых полимерных электретных композитов на основе реактопластов для очистки сточных вод электрохимических производств.

Сорбционные свойства контролировали по уменьшению концентрации катионов никеля в водных растворах методом спектрофотометрического титрования. Суть метода заключается в приготовлении качественного раствора на ионы никеля и измерение его оптической плотности. Необходимость данных операций обусловлена тем, что при низких концентрациях сульфата никеля в водном растворе отсутствует какой-либо окрас и оптическая плотность раствора практически равна нулю.

Для получения точной зависимости между оптической плотностью и концентрацией сульфата никеля была построена градуировочная кривая, имеющая отчётливый линейный характер во всём диапазоне рабочих концентраций.

Для установления кинетической зависимости сорбцию проводили при разной продолжительности в диапазоне от 5 до 60 мин. По полученным таким образом результатам определяли концентрацию сульфатов в водном растворе непосредственно по градуировочной кривой (рис. 1.).

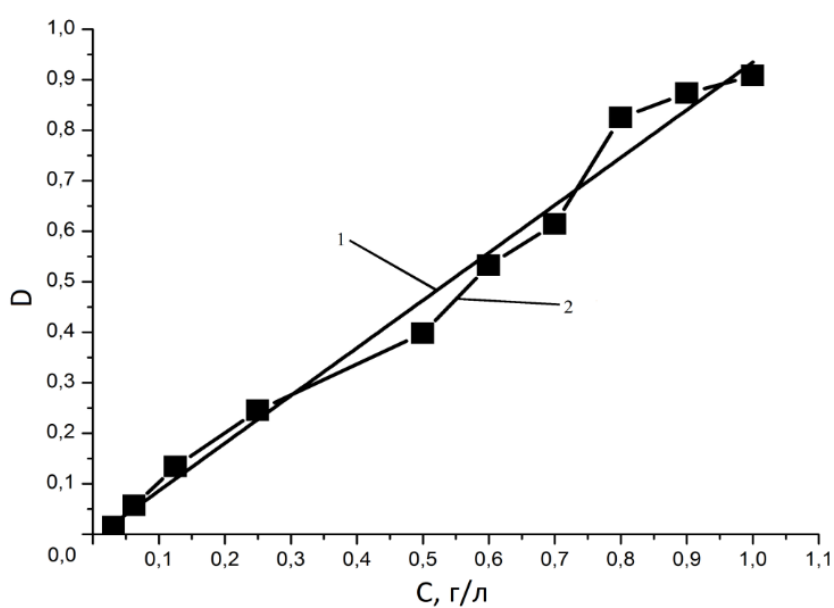

Рисунок 1. Градуировачный график: 1 - усреднённье значение; 2 - экспериментальные точки

Диапазон начальных концентраций модельных растворов находится в пределах от 0,1 до 1 г/л, что совпадает и даже превышает диапазон концентраций сульфатов в сточных водах электрохимический производств. Например, концентрация сульфатов до очистки в сточных водах Пензенского предприятия АО ПО «Электроприбор» составляет: минимум - 0,138 г/л; максимум - 0,565 г/л; среднее - 0,315 г/л. После очистки концентрация составляет 0,070 г/л.

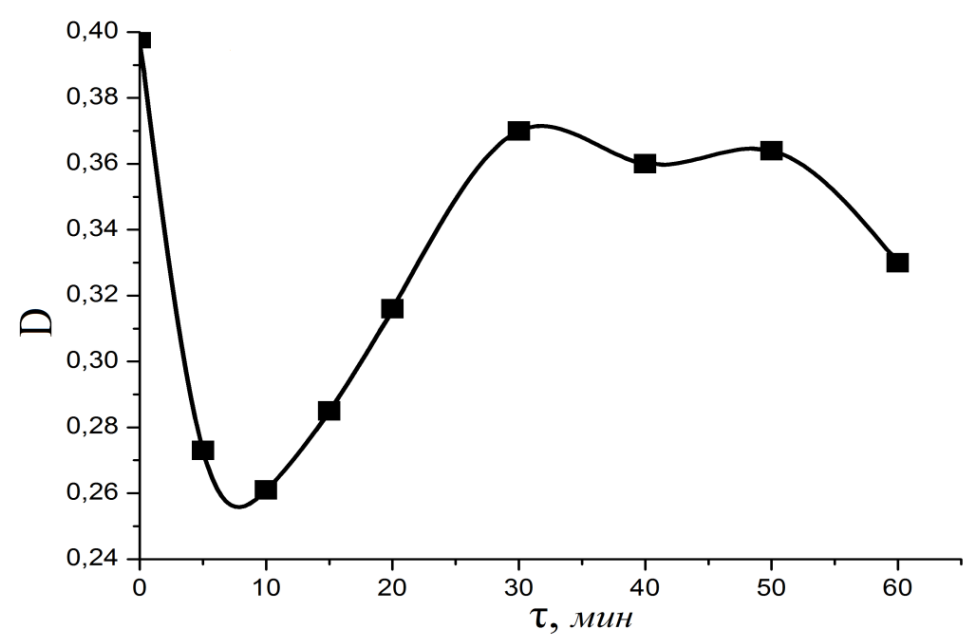

Рисунок 2. Зависимость оптической плотности от продолжительности сорбции при начальной концентрации сульфата никеля 0,5 г/л 
Кривая зависимости оптической плотности от продолжительности сорбции (рис. 2) имеет ярко выраженный минимум, в промежутке от 5 до 15 минут, что соответствует оптимальной продолжительности сорбции. Такой промежуток времени оптимален для быстрой очистки сточный вод. Иными словами, полимерные электреты в качестве сорбентов возможно применять для тонкой очистки сточных вод, а не для глубокой (грубой) очистки. Дальнейшее понижение оптической плотности, а, следовательно, и уменьшение степени извлечения (табл. 1.), свидетельствует о том, что продолжительное нахождение сорбента в растворе может приводить к десорбции.

Таблица 1

Условия сорбциии и характеристики раствора сульфата никеля после сорбции

\begin{tabular}{|c|c|c|c|c|}
\hline $\begin{array}{c}\text { Продолжсительность } \\
\text { сорбции, мин }\end{array}$ & $\begin{array}{c}\text { Оптическая } \\
\text { потность }\end{array}$ & Концентрация, г/л & $\begin{array}{c}\text { Снижение } \\
\text { концентрачии, \% }\end{array}$ & $\begin{array}{c}\text { Степень } \\
\text { излечения в } \\
\text { долях }\end{array}$ \\
\hline 0 & 0,398 & 0,500 & - & - \\
\hline 5 & 0,273 & 0,298 & 40,4 & 0,314 \\
\hline 10 & 0,261 & 0,284 & 43,2 & 0,344 \\
\hline 15 & 0,285 & 0,312 & 37,6 & 0,284 \\
\hline 20 & 0,316 & 0,344 & 31,2 & 0,206 \\
\hline 30 & 0,370 & 0,402 & 19,6 & 0,070 \\
\hline 40 & 0,360 & 0,391 & 21,8 & 0,095 \\
\hline 50 & 0,364 & 0,396 & 20,8 & 0,085 \\
\hline
\end{tabular}

Концентрация ионов никеля после сорбции в стационарном режиме приближается к концентрации после очистки сточных вод на промышленных предприятиях, но всё же не достигает её. Для увеличения степени извлечения необходимо использовать приёмы, интенсифицирующие процесс сорбции, например, перемешивание раствора.

$$
* * *
$$

1. Лимаренко Н.А. Исследование диэлектрических свойств электретов на основе эпоксидных полимеров / Н.А. Лимаренко, Е.Н. Мочалова, М.Ф. Галиханов, Р.Я. Дебердеев // Вестник казанского технологического университета. - 2013. - Т. 16. - № 2. - С. 126-128;

2. Студенцов В.Н. Разработка технологии полимерного электрета для микрофонов на основе реактопласта / В.Н. Студенцов, В.В. Марценюк // Вестник Санкт-Петербургского государственного университета технологии и дизайна. Серия 1: Естественные и технические науки. - 2016. - № 3. - С. 103-108;

3. Мочалова Е.Н. Электретные и прочностные свойства полимерных материалов на основе эпоксидного олигомера и аминных отвердителей / Е.Н. Мочалова, М.Ф. Галиханов, Я.К. Микрюкова // Журнал прикладной химии. - 2019. - Т. 92. - № 11. - С. 1394-1400;

4. Микрюкова Я.К. Исследование влияния содержания отвердителя аминного типа на электретные характеристики полимерных материалов на основе эпоксидного олигомера / Я.К. Микрюкова, Е.Н. Мочалова, М.Ф. Галиханов // Вестник технологического университета. - 2019. - Т. 22. - №. 2. - С. 86-88;

5. Студенцов В.Н. Разработка технологии полимерного электрета на основе реактопласта/ В.Н. Студенцов, В.В. Марценюк // VII Международная конференция «Перспективные полимерные композиционные материалы. Альтернативные технологии. Переработка. Применение. Экология ("КОМПОЗИТ-2016")». - Энгельс, 28-30 июня 2016 г. - С. 73-77;

6. Студенцов В.Н. Оценка электретных свойств электрохимическим способом/ В.Н. Студенцов, В.В. Марценюк, Е.Ю. Горбачёва, Н.В. Горшков // III Международная конференция молодых ученых «Актуальные проблемы теории и практики электрохимических процессов». - Энгельс, 25-28 апреля 2017 г. C. 61-64. 